\title{
Contribution to the Physicochemical and Organoleptic Study of Two Olive Oils of Traditional and Industrial Extraction of the Wilaya of Tlemcen
}

\author{
Sarra Selka ${ }^{*}$, Amal Khayra Tchouar ${ }^{2}$, Sidi Mohamed Amrani ${ }^{3}$ \\ ${ }^{1}$ Laboratory of Physiology, Physiopathology and Biochemistry of Nutrition (PPABIONUT), Department of Biology, Faculty of \\ Natural and Life Sciences, Earth and Universe, Abou-Bekr Belkaïd University Tlemcen, Tlemcen, Algeria \\ ${ }^{2}$ Department of Agroforestry, Faculty of Natural and Life Sciences, Earth and Universe, Abou-Bekr Belkaïd University Tlemcen, \\ Tlemcen, Algeria \\ ${ }^{3}$ Department of Biology, Plant Ecology Laboratory, Faculty of Natural and Life Sciences, Earth and Universe, Abou-Bekr Belkaïd \\ University Tlemcen, Tlemcen, Algeria \\ Email: ${ }^{\star}$ s.selka.sek@gmail.com
}

How to cite this paper: Selka, S., Tchouar, A.K. and Amrani, S.M. (2019) Contribution to the Physicochemical and Organoleptic Study of Two Olive Oils of Traditional and Industrial Extraction of the Wilaya of Tlemcen. Journal of Agricultural Chemistry and Environment, 8, 107-114.

https://doi.org/10.4236/jacen.2019.82009

Received: March 13, 2019

Accepted: May 27, 2019

Published: May 30, 2019

Copyright $\odot 2019$ by author(s) and Scientific Research Publishing Inc. This work is licensed under the Creative Commons Attribution International License (CC BY 4.0).

http://creativecommons.org/licenses/by/4.0/

\begin{abstract}
Virgin olive oil is obtained from the fruit of the olive tree, and only using physical processes, without resorting to refining steps, the absence of the latter allows the olive oil to retain all its antioxidants. This work is a contribution to the characterization of the properties of olive oil in the region of Tlemcen. They relate more particularly to the comparison of the physicochemical properties of two oils, one from traditional extraction and the other from industrial extraction. To do this, the first objective of studies of the two chains of transformation (traditional and industrial) was made followed by a physicochemical and organoleptic comparison of these two oils of olives, to conclude on the advantages and disadvantages of each of the two processes.
\end{abstract}

\section{Keywords}

Olive Oil, Craft, Industrial, Physicochemical Analysis, Sensory Analysis

\section{Introduction}

Olive oil is the Mediterranean product par excellence. It is found throughout history, from Greek civilization to the present day. It is the main source of fat from the Cretan diet or the Mediterranean diet that are well known for their beneficial effects on human health. Olive oil is an interesting product from a nu- 
tritional point of view, but first for its fatty acid composition. Indeed, it is largely unsaturated and contains a small part of essential fatty acids [1].

The quality of olive oil varies not only according to the variety, the soil and the climatic conditions but also with many factors relating to the cycle of production, processing and marketing of olives and oils [2].

Our study is based on the comparison between two olive oils of industrial and traditional extraction from the point of view physicochemical and organoleptic, by specifying their advantages and disadvantages, as well as the good quality management of the oils produced.

The samples were taken from different regions of the wilaya of Tlemcen: Sabra, Ain Defla and Benisnouss. Compliance of oil with C.O.I. (International Olive Oil Council) and C.A. (Codex Alimentarius) requires the determination of certain physical parameters (Potential hydrogen, Water content, Absorbance in the ultra violet), chemical (acid index, saponification index, peroxide index, iodine index, ester index) and organoleptic.

\section{Materials and Methods}

\subsection{Origin of Samples}

The olive oils studied come from three different oil mills: Sabra, Ain defla, Tafessra, some of which are artisanal and some industrial, these three regions represent the most important olive oil production sites in the wilaya of Tlemcen.

\subsection{Physicochemical Characterization}

\subsubsection{Acid Index}

The acid index (IA) is the number of milligrams of potassium hydroxide required for the neutralization of free acids contained in one gram of fat [3].

\subsubsection{Saponification Index}

The saponification index (IS) corresponds to the number of milligrams of potash required to saponify the fatty acids contained in one gram of fat. This value is all the higher than the fatty acids are of lower molecular weight [4].

\subsubsection{Peroxide Index}

The peroxide index (IP) is a measure for estimating the amount of peroxide present in a fat [3]. A sample is dissolved in a mixture of acetic acid and chloroform, then treated with a potassium iodide solution. The liberated iodine is treated with a solution of sodium thiosulfate in the presence of starch stains (colored indicator) [5].

\subsubsection{Iodine Index}

Iodine index (II) generally measures the degree of unsaturation of a fat by determining the number of grams of iodine binding to the double bonds present in $100 \mathrm{~g}$ of lipids [3].

\subsubsection{Absorbance by Spectrophotometry}

Extinction at $232 \mathrm{~nm}$ and $270 \mathrm{~nm}$ of a crude fat can be considered as an image of 
its oxidation state; more the extinction at $232 \mathrm{~nm}$ is strong, the more olive oil is rich in secondary oxidation product [6].

\subsubsection{Water Content}

It consists of causing water to start by heating a known quantity of oil until the water is eliminated completely [7].

\subsubsection{Hydrogen Potential}

Hydrogen potential $(\mathrm{PH})$ gives an indication of the acidity or alkalinity of the medium, it is determined from the amount of free hydrogen ions $(\mathrm{H}+)$ contained in the olive oil [8].

\subsection{Sensory Analysis}

The organoleptic characteristics of olive oil are related to the variety of fruits, their degree of maturity, at harvest time, ecological factors, variations in harvesting and fruit storage operations, and the variability of extraction and storage processes of olive oil [9].

The test used sets the different tasting criteria: taste, color, appearance and smell according to C.O.I. Candidates must taste the samples submitted to them and see how they find the product by checking the statement.

\section{Results and Discussion}

\subsection{Results of Physico-Chemical Analyzes}

Traditional olive oils represent higher acidity compared to industrial olive oils (Figure 1 and Figure 2), but remain fit for consumption, certainly due to the prolonged storage of olives in the open, the lack of washing and sorting, the lack of mastery of the techniques of purification and incomplete separation of the fruit juice of the margines alters the taste of the oil and increases its acidity.

The results show that all analyzed samples have varying saponification (Figure 3). The impurity percentage, Peroxide and iodine indices meet the standards too (Figures 4-6), which allows us to consider them as being of good quality. On the other hand, oil of Ain Defla region is a little higher than the norms which imply that it is easily alterable and less stable, which will facilitate their rancidity.

The absorbance in the ultraviolet, the water content and the $\mathrm{pH}$ of our samples is in the norms (Figures 7-9).

The detailed numerical values of these results are shown in Table 1, Table 2 gives the values according to the standards.

\subsection{Sensory Results}

The tasting analysis highlights a superiority of the traditional extraction olive oil characterized by a low fruity taste and an acceptable odor. The acceptability of it by the taster is well appreciated, contrariwise all tasters criticize this one for being too strong. On the other hand, olive oil of industrial extraction, presents a 
normal coloring, but a taste and an unacceptable odor. Its acceptability by the taster is not well appreciated.

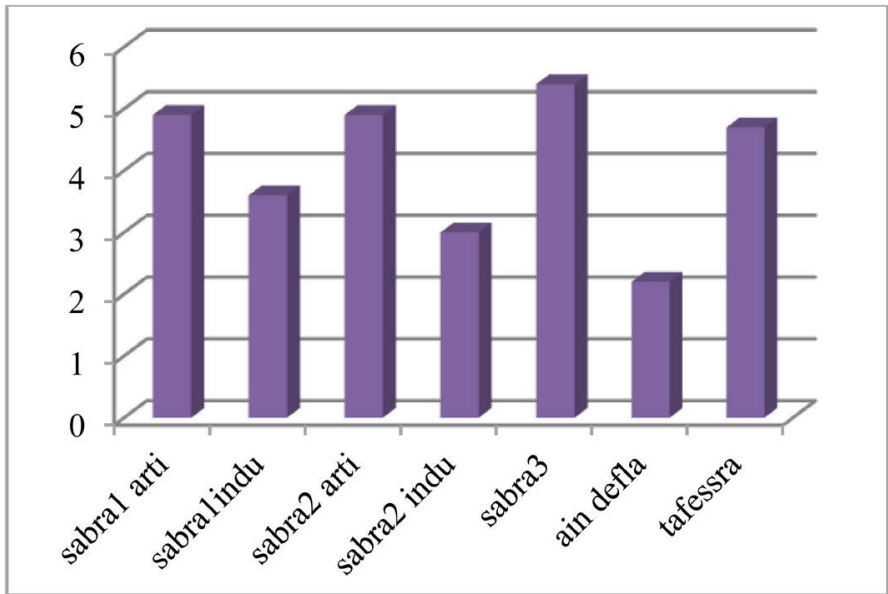

Figure 1. Acid index.

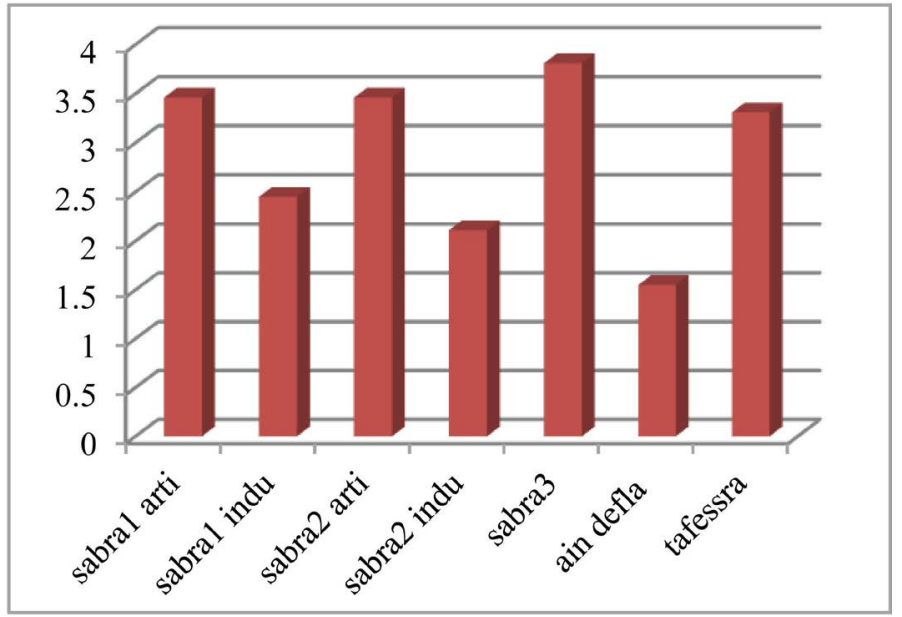

Figure 2. \% of oleic acid.

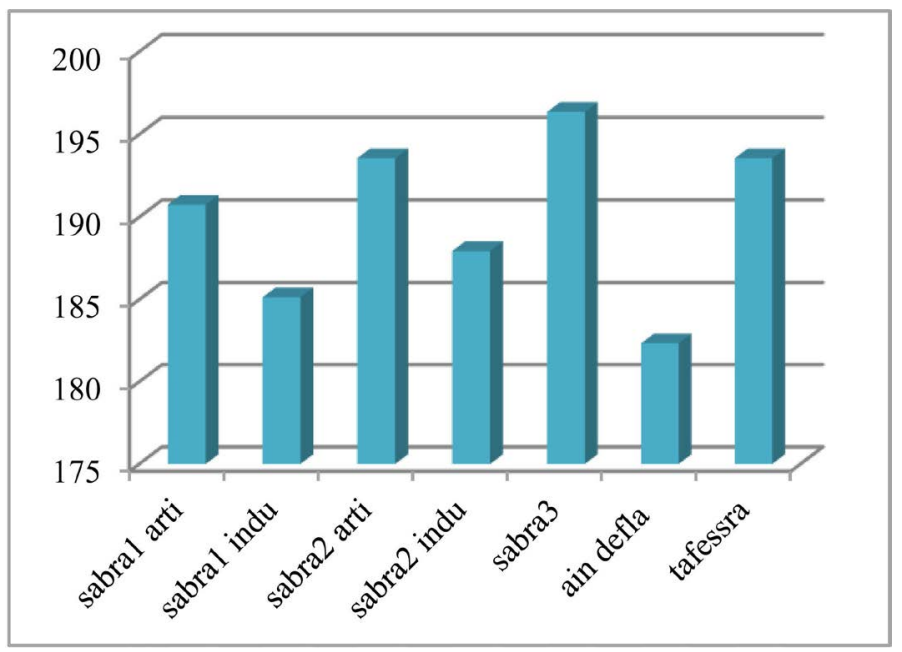

Figure 3. Saponification index. 


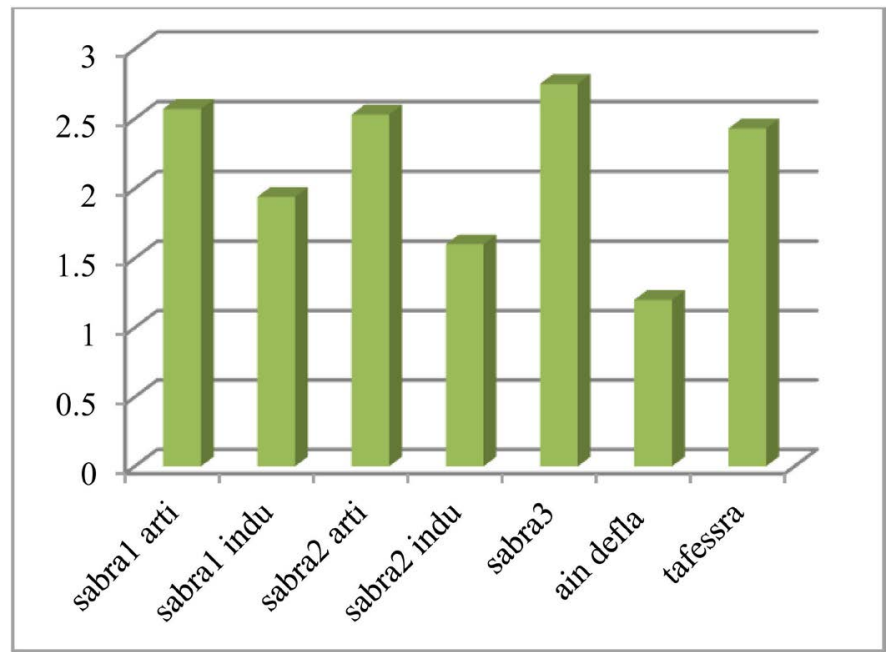

Figure 4. \% of impurities.

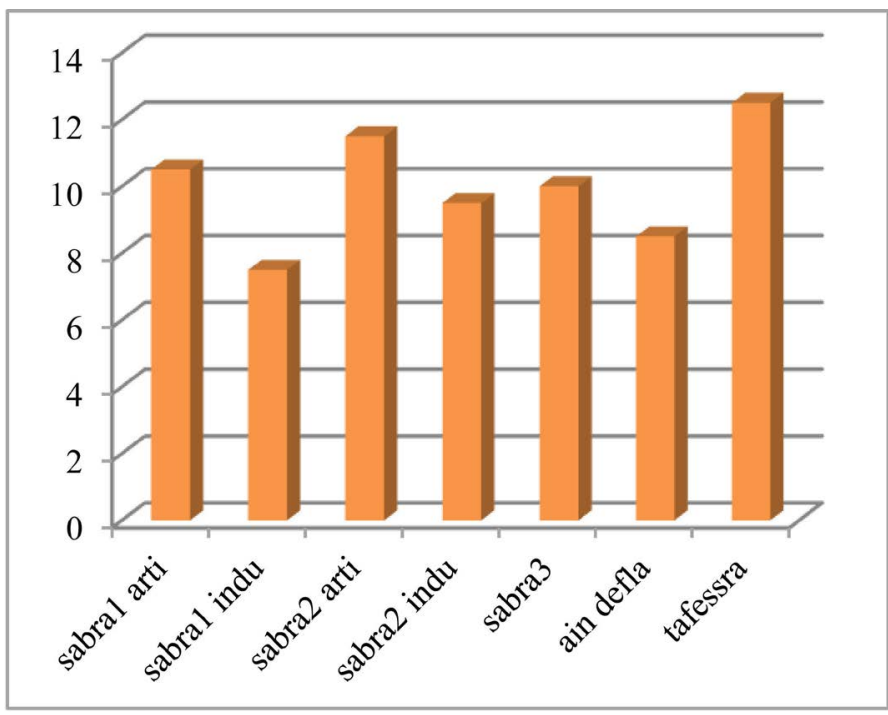

Figure 5. Peroxide index.

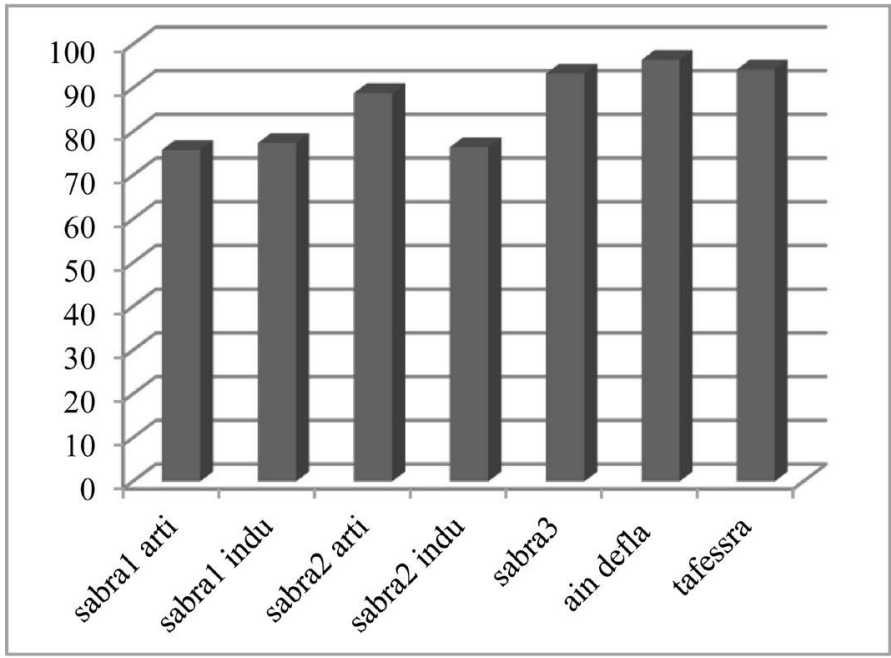

Figure 6. Indice d'iode. 


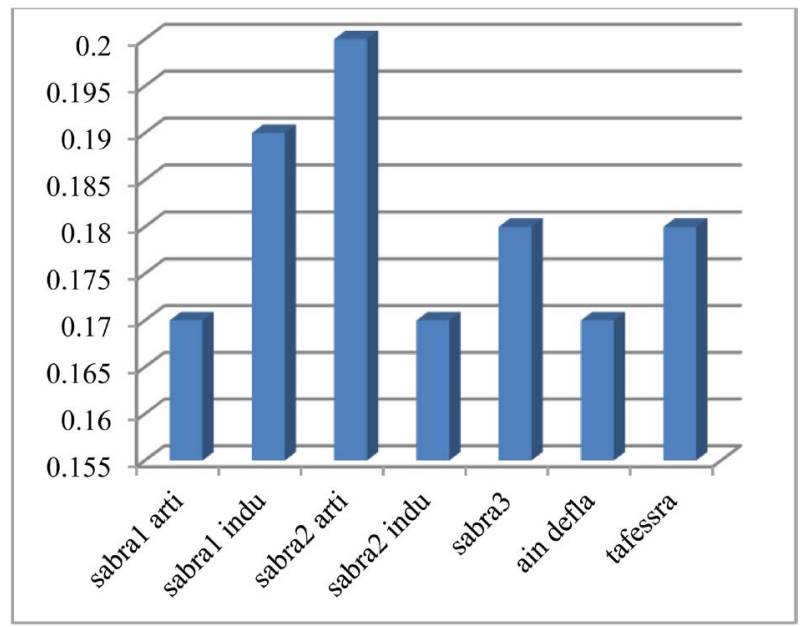

Figure 7. Water content.

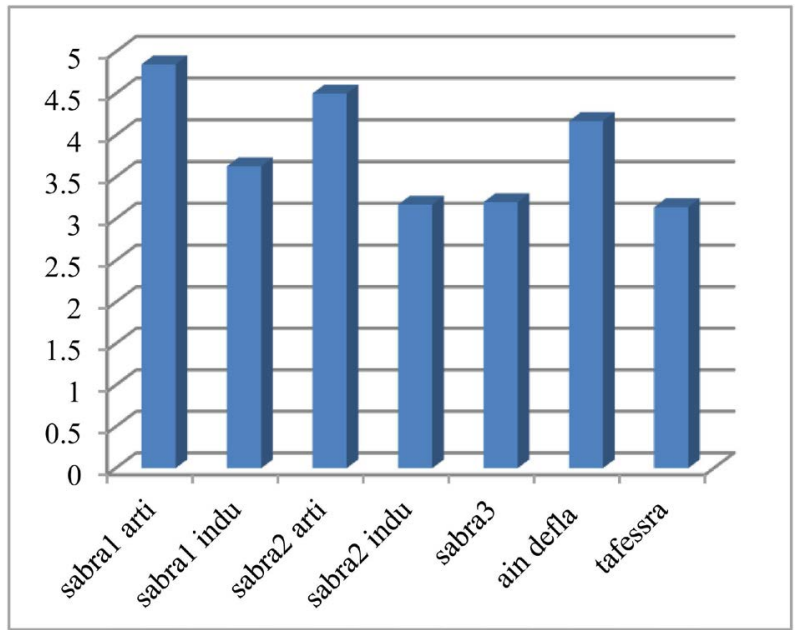

Figure 8. Hydrogen potential $(\mathrm{pH})$.

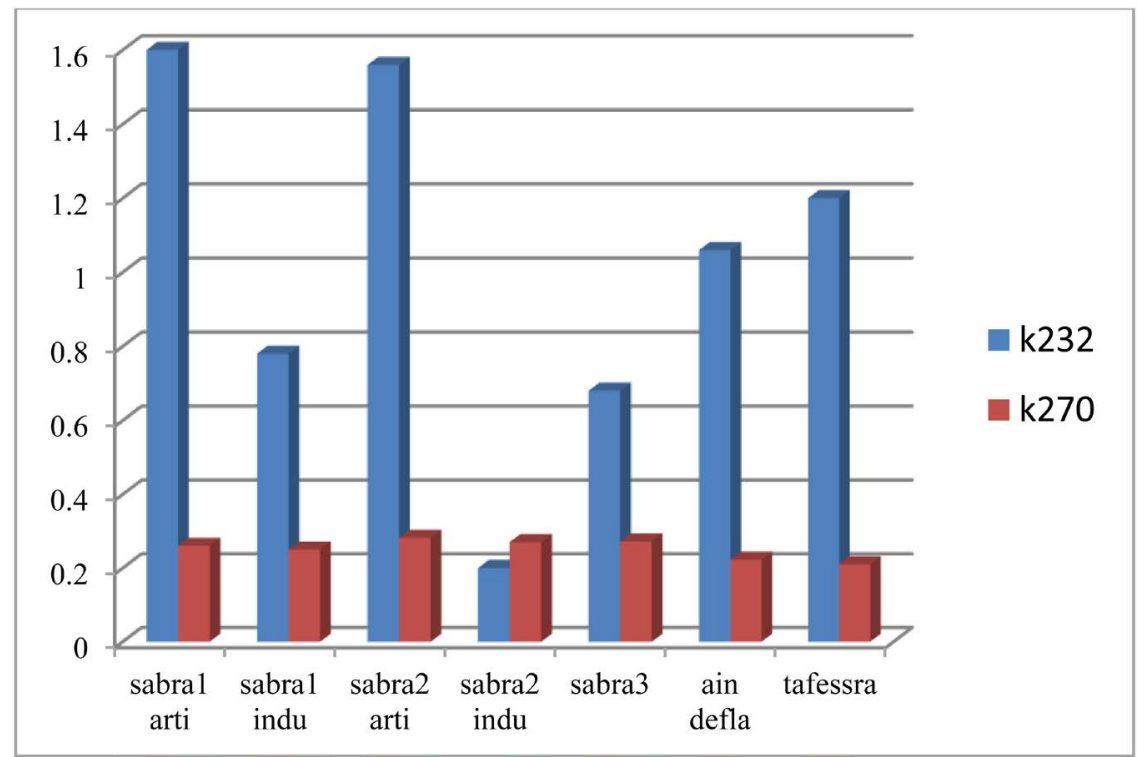

Figure 9. Absorbance spectrophotometer at $232 \mathrm{~nm}$ and $270 \mathrm{~nm}$. 
Table 1. Summary table of different chemical and physical characteristics of the seven samples studied.

\begin{tabular}{|c|c|c|c|c|c|c|c|}
\hline Characters $\quad$ Origins & $\begin{array}{c}\text { Traditional } \\
\text { Sabra } 1\end{array}$ & $\begin{array}{l}\text { Industrial } \\
\text { Sabra } 1\end{array}$ & $\begin{array}{c}\text { Traditional } \\
\text { Sabra } 2\end{array}$ & $\begin{array}{l}\text { Industrial } \\
\text { Sabra } 2\end{array}$ & $\begin{array}{l}\text { Traditional } \\
\text { Sabra } 3\end{array}$ & $\begin{array}{l}\text { Industrial } \\
\text { Ain defla }\end{array}$ & $\begin{array}{c}\text { Traditional } \\
\text { Tafessra }\end{array}$ \\
\hline \multicolumn{8}{|l|}{-Chemical: } \\
\hline Acid index & 4.9 & 3.6 & 4.9 & 3 & 5.4 & 2.2 & 4.7 \\
\hline Free acidity & 3.46 & 2.54 & 3.46 & 2.11 & 3.81 & 1.55 & 3.31 \\
\hline Saponification index & 190.7 & 185.14 & 193.56 & 187.95 & 196.36 & 182.34 & 193.56 \\
\hline Ester index & 185.85 & 181.54 & 188.66 & 184.95 & 190.96 & 180.14 & 188.86 \\
\hline$\%$ impurity & 2.57 & 1.94 & 2.53 & 1.6 & 2.75 & 1.2 & 2.43 \\
\hline Peroxide index & 10.5 & 7.5 & 11.5 & 9.5 & 10 & 8.5 & 12.5 \\
\hline Iodine index & 75.8 & 77.4 & 88.3 & 76.45 & 93.27 & 96.44 & 94.2 \\
\hline \multicolumn{8}{|l|}{-Physical: } \\
\hline Water content & 0.17 & 0.19 & 0.2 & 0.17 & 0.18 & 0.17 & 0.18 \\
\hline Hydrogen potential(pH) & 3.63 & 4.85 & 3.17 & 4.5 & 3.2 & 4.17 & 3.14 \\
\hline \multicolumn{8}{|l|}{ Absorbance in the UV } \\
\hline at $232 \mathrm{~nm}$ & 1.6 & 0.78 & 1.56 & 0.2 & 0.68 & 1.6 & 1.2 \\
\hline at $270 \mathrm{~nm}$ & 0.26 & 0.25 & 0.282 & 0.27 & 0.272 & 0.222 & 0.21 \\
\hline
\end{tabular}

Table 2. Normal values of physicochemical characteristics.

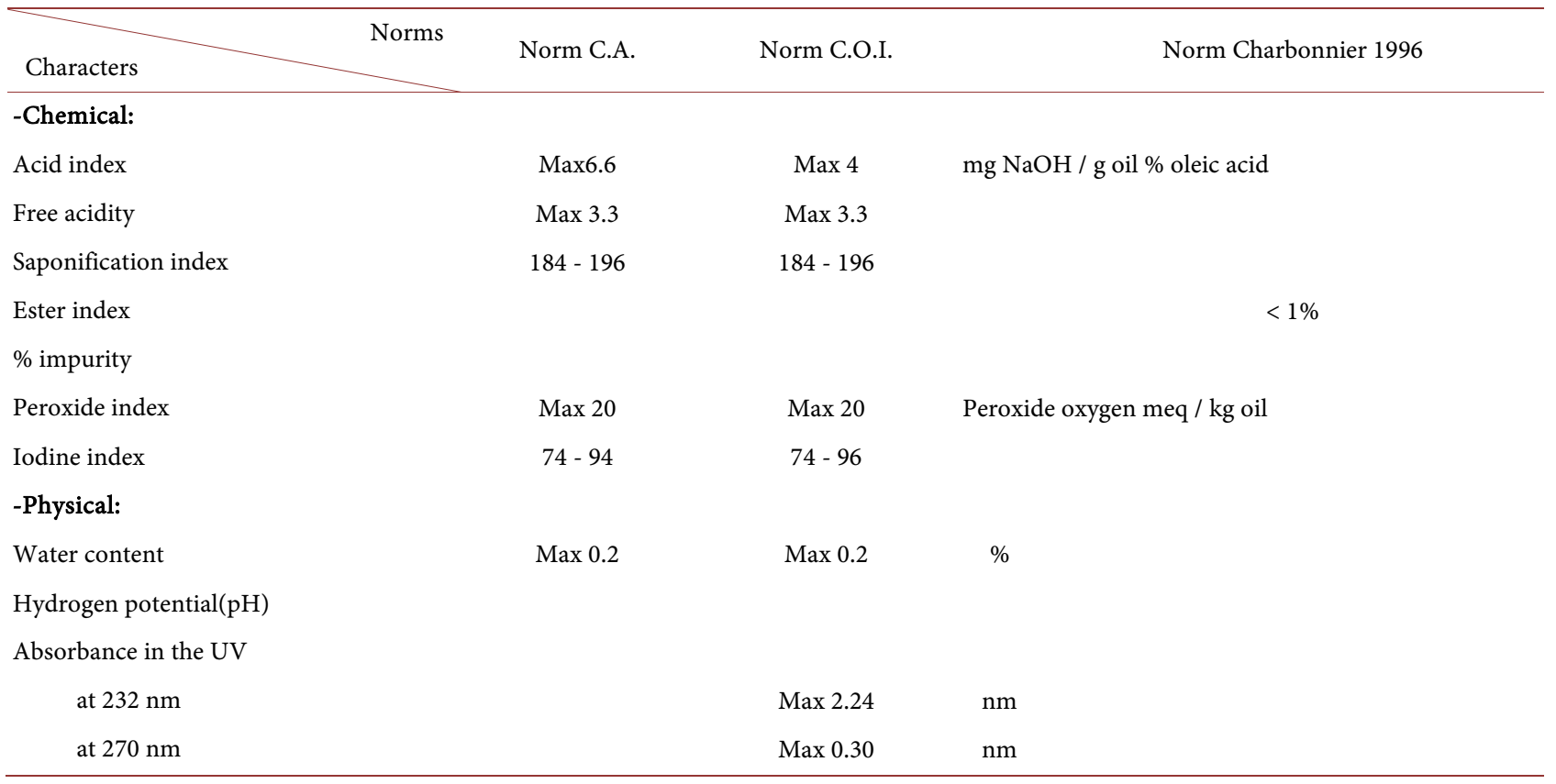

\section{Conclusions}

The good quality of olive oil depends on several factors, first the good quality of the olive species, picking, transporting it to oil mills, the manufacturing process used as well as the preservation and packaging.

In this study, the quality of olive oil is measured by physicochemical and or- 
ganoleptic characteristics, mainly related to the raw material (olive) and the extraction process.

The results obtained showed that among the oils analyzed, some are impure and have high levels of acidity that do not meet standards, which is certainly due to the geographical origin of the olives, lack of attention to the harvest, as well as the conservation and processing of olives.

For this, the quality department should oblige the olive oil seller to guarantee the purity and to improve the packaging of his product, and this is certainly not due to a requirement, but for one's own consumption from the nutritional point of view.

\section{Conflicts of Interest}

The authors declare no conflicts of interest regarding the publication of this paper.

\section{References}

[1] Sebastian, V. (2010) Enrichissement nutritionnel de l'huile d'olive: Entre Tradition et Innovation. Ph.D. Dissertation. University Avignon and the Pays de Vaucluse, 160.

[2] Alkama, O. (1989) Etude comparée des propriétés physicochimiques et organoleptiques de deux huiles d'olives vierges d'extraction industrielle et artisanale. State Engineer's Thesis in Agronomy University of Mostaganem, 65.

[3] Lion, P.H. (1955) Travaux pratiques de chimie organique. Ed. Dunod, Paris.

[4] Afnor (1978) Recueil des Normes françaises des corps gras. Graines oléagineuses produits dérivés. Ed.Paris.

[5] Bouhadjra, K. (2011) Etude de l'effet des antioxydants naturels et de synthèse sur la stabilité oxydative de l'huile d'olive vierge. Memory of Magister. Chemistry, University of Tizi Ouzou, 96.

[6] Commission of the European Communities (1991) Regulation (CE) n $2568 / 91$ from the Commission of July 11, 1991 Relating to Characteristics of Olive Oils and Olive Pomace Oils As Well As the Related Methods of Analysis. (J.O.L. 248 of 5/9/1991,1).

[7] Benosman, R. and Mamchaoui (2005) Contribution au contrôle de qualité physico-chimique d'échantillons d'huiles d'olives. Engineer's Memory. Biology, University of Tlemcen, 103 .

[8] Audigie, C.L., Dupont, G. and Zouszain, F. (1984) Principes des méthodes d'analyse biochimique. Volume 1. Ed. Doin, 136-155.

[9] International Oil Council (1985) OLIVEA Review 2nd Year n 6 April. 